\title{
A ADOÇÃO DO CPC PME - CONTABILIDADE PARA PEQUENAS E MÉDIAS EMPRESAS
}

\author{
ADOPTION OF CPC SMES - ACCOUNTING FOR SMALL AND MEDIUM-SIZED \\ ENTITIES
}

\author{
Camilla Teles de Araújo Faria \\ camillateles@hotmail.com \\ Universidade Federal de Uberlândia
}

\author{
Denise Mendes da Silva \\ denysemendes03@gmail.com \\ Universidade Federal de Uberlândia
}

\section{RESUMO}

Com a crescente abertura da economia brasileira aos mercados internacionais, surge a necessidade de convergência para normas internacionais de contabilidade. O CPC (Comitê de Pronunciamentos Contábeis) é o órgão que centraliza a emissão de pronunciamentos técnicos, interpretações e orientações técnicas contábeis no Brasil em conformidade com o conjunto de normas contábeis internacionais. Em $1^{\circ}$ de janeiro de 2010 entrou em vigor o CPC PME Contabilidade para Pequenas e Médias Empresas - que dispõe sobre a forma como devem ser guiadas as práticas contábeis destas empresas. O objetivo geral deste estudo é investigar quais fatores podem influenciar os contadores das pequenas e médias empresas da cidade de Uberlândia/MG a adotarem o CPC PME na elaboração das demonstrações contábeis. Adicionalmente, como objetivo específico, deseja-se conhecer se os contadores que afirmam adotar o CPC PME aplicam a norma adequadamente e quais seriam as principais dificuldades da adoção deste pronunciamento. Para isso foi aplicado um questionário aos contadores responsáveis por escritórios de contabilidade em Uberlândia/MG. A amostra é constituída por 84 entidades prestadoras de serviços contábeis e os dados foram analisados por meio de estatísticas descritivas e do teste Qui-quadrado. Os resultados demonstraram que apenas $15 \%$ dos contadores da amostra adotaram o CPC PME, porém há uma fragilidade no conhecimento destes profissionais a respeito da norma. Os principais fatores que influenciam a adoção do CPC PME são a formação acadêmica dos contadores e o nível de conhecimento acerca da norma.

Palavras-chave: Contabilidade. Pequenas e Médias Empresas. CPC PME.

\section{ABSTRACT}

With the increasing openness of the Brazilian economy to international markets, there is necessity the convergence of accounting to the international standards. The CPC (Accounting Pronouncements Committee) is the organization that centralizes issuing pronouncements, interpretations and technical accounting guidance in Brazil in accordance with the set of international accounting standards. On January 1, 2010 came into force the CPC SMEs Accounting for Small and Medium-sized Entities - which governs the way it should be guided accounting practices of these companies. The aim of this study is to investigate which factors may influence the accountants of small and medium enterprises in Uberlândia/MG to adopt the CPC SMEs in preparing the financial statements. Additionally, as a specific goal, would like to know if the accountants that claim to adopt the CPC SMEs apply the rule properly and what are 
the main difficulties of this pronouncement. For this, a questionnaire to accountants responsible for accounting firms was applied in Uberlândia/MG. The sample consists of 84 entities providing financial services and data were analyzed using descriptive statistics and Chi-square test. The results showed that only $15 \%$ of the sample accountants adopted the CPC SMEs, but there is a weakness in knowledge of these professionals about the standard. The main factors influencing the adoption of CPC SMEs are the academic education of accountants and the level of knowledge about the norm.

Keywords: Accounting. Small and Medium-sized Entities. CPC SMEs.

Artigo recebido em: 09/03/2014; Aceito em: 13/11/2014

\section{INTRODUÇÃO}

No Brasil, de acordo com o SEBRAE (Serviço Brasileiro de Apoio às Micro e Pequenas Empresas), $99 \%$ das empresas são de pequeno e médio porte e estas são responsáveis por mais da metade (52\%) dos empregos formais. Nos últimos três anos, as pequenas e médias empresas cresceram mais de $60 \%$ no país, sendo que de $\mathrm{R} \$ 1,2$ bilhão de negócios fechados pelas administrações públicas Federal, Estaduais e Municipais, 25\% foram de serviços e produtos de pequenas e médias empresas. Esses dados revelam a importância dessas empresas para o país e, também, a necessidade de procedimentos adequados de prestação de contas, que possam atender aos diversos usuários da informação (investidores, financiadores e outros credores) em qualquer lugar do mundo. Essa prestação de contas é uma das funções da contabilidade.

Em 2005 foi criado no Brasil o CPC (Comitê de Pronunciamentos Contábeis) devido às necessidades de conduzir a convergência para as normas internacionais de contabilidade, as International Financial Reporting Standards, ou simplesmente IFRS. O CPC centraliza a emissão de pronunciamentos técnicos, interpretações e orientações técnicas contábeis de forma democrática, uma vez que as referidas normas são submetidas a audiências públicas antes de serem publicadas.

A necessidade da convergência da contabilidade aos padrões internacionais se dá pela crescente abertura da economia brasileira aos mercados internacionais, tornando possível a compreensão das informações contábeis por usuários estrangeiros. No Brasil, além das empresas de capital aberto ou sociedades de grande porte, as pequenas e médias empresas também devem adotar as normas emanadas pelo CPC, por meio de um Pronunciamento Técnico Contábil específico, o CPC PME - Contabilidade para Pequenas e Médias Empresas, aprovado em dezembro de 2009 e que entrou em vigor a partir de $1^{\circ}$ de janeiro de 2010.

A contabilidade no Brasil foi, durante muitos anos, fortemente atrelada a aspectos fiscais e as empresas, notadamente as pequenas e médias, elaboravam suas demonstrações contábeis basicamente para atender as exigências do fisco (KLEIN JÚNIOR; SOUZA, 2013). Entretanto, com a aprovação do CPC PME, surgiu a necessidade de uma mudança de postura dos profissionais contábeis que, além de observar as regras do fisco, passaram a ter que exercer julgamentos responsáveis para o registro das transações econômicas na contabilidade das empresas. As mudanças foram significativas, principalmente no que tange às demonstrações contábeis que devem ser elaboradas e registro de alguns itens, como estoques e imobilizado, 
por exemplo. Alguns profissionais contábeis, porém, podem não ter percebido o impacto real dessas alterações e/ou encontraram dificuldades para aplicar o CPC PME.

Na cidade de Uberlândia, estado de Minas Gerais, conforme informações do SEBRAE Minas, $80 \%$ das micro e pequenas empresas conseguem ultrapassar a barreira dos dois anos, que é considerada uma época decisiva na manutenção da empresa. Em 2013, a Secretaria Municipal de Desenvolvimento Econômico e Turismo de Uberlândia lançou o Pró-micro - Programa Municipal de Desenvolvimento da Microempresa, Empresa de Pequeno Porte e Microempreendedor Individual. O Pró-micro consiste em diversas ações de políticas públicas que visam o desenvolvimento da micro e pequena empresa e do empreendedor individual. $\mathrm{O}$ programa foi criado com o objetivo de elevar a cidade de Uberlândia como referência nacional em desenvolvimento da micro e pequena empresa, por meio da promoção de políticas públicas e apoio a iniciativas de fomento ao setor, com foco no resultado empresarial. A partir de uma Lei Geral Municipal aprimorada, Uberlândia visa disponibilizar novos instrumentos de incentivo às micro e pequenas empresas, ampliando a formalização, o faturamento dessas empresas e os empregos gerados. Tais empresas são elegíveis à adoção do CPC PME.

Nesse contexto, deseja-se responder à seguinte questão: quais fatores podem influenciar os contadores das pequenas e médias empresas da cidade de Uberlândia/MG a adotarem o CPC PME na elaboração das demonstrações contábeis? Sendo assim, o objetivo geral deste estudo é investigar quais fatores podem influenciar os contadores das pequenas e médias empresas da cidade de Uberlândia/MG a adotarem o CPC PME na elaboração das demonstrações contábeis. Adicionalmente, como objetivo específico, deseja-se conhecer se os contadores que afirmam adotar o CPC PME aplicam a norma adequadamente e quais seriam as principais dificuldades da adoção deste pronunciamento. Para isso foi aplicado um questionário aos contadores responsáveis por escritórios de contabilidade em Uberlândia/MG.

As principais contribuições esperadas desta pesquisa são: oferecer subsídios para o conhecimento acerca da aplicação do CPC PME, pois a quantidade de estudos relacionados a esta temática ainda é pequena; identificar se características dos contadores, tais como, formação acadêmica, tempo de atuação profissional e nível de conhecimento a respeito do CPC PME estão associadas à adoção da norma; identificar se características da organização contábil, como quantidade total de clientes e quantidade de clientes que são pequenas e médias empresas relacionam-se com a adoção do CPC PME; investigar demais fatores que podem influenciar a adoção do CPC PME, como custos com pessoal e estrutura, qualificação e treinamento, exigências de órgão externos etc.; discutir se os escritórios que afirmam adotar o CPC PME na elaboração das demonstrações contábeis de seus clientes aplicam a norma adequadamente.

O trabalho está estruturado em cinco seções, incluindo-se esta introdução. Na seção dois é realizada a revisão da literatura, que subsidia as discussões; na seção três são descritos os aspectos metodológicos; na quarta seção é feita a apresentação e análise dos resultados e na quinta seção são feitas as considerações finais e propostas para futuras pesquisas.

\section{REVISÃO DA LITERATURA}

\subsection{Contabilidade para Pequenas e Médias Empresas}

A contabilidade possibilita à empresa coletar, processar e relatar informações para uma variedade de decisões operacionais e administrativas, porém é perceptível a imagem para as pequenas empresas de que a contabilidade apenas existe para o atendimento das exigências

R. Cont. Ufba, Salvador-Ba, v. 8, n. 3, p. 75 - 91, set-dez 2014 
fiscais, ficando relegado, ao segundo plano, o atendimento às necessidades da gestão dos negócios (STROEHER; FREITAS, 2008).

O artigo 177 da Lei 11.638, aprovada em 2007, prevê a segregação da escrituração mercantil da escrituração fiscal, com o objetivo de minimizar as interferências do fisco na elaboração das demonstrações financeiras, representando um marco no processo de convergência das normas contábeis brasileiras às normas internacionais.

Segundo Lopes e Martins (2007) a contabilidade tem a função clara e objetiva de servir às necessidades dos usuários, rejeitando-se a ideia da 'contabilidade pela contabilidade'. Os autores ressaltam que a função da contabilidade é bastante ampla, na medida em que é responsável pelo fornecimento de informações de caráter operacional e não somente financeiro. Lunardi, Dolci e Maçada (2010, p. 7) lembram que muitos problemas relacionados às pequenas e médias empresas são únicos e, portanto, merecem pesquisas específicas para tentar preencher essas lacunas. As pequenas e médias empresas caracterizam-se pelo alto nível de incerteza em seu ambiente, influenciado por mudanças extremamente rápidas, o que dificulta ainda mais o gerenciamento de empresas que não possuem uma visão estratégica - característica de muitas delas - as quais, portanto, não percebem a necessidade de buscar possibilidades futuras.

Para regulamentar a contabilidade das pequenas e médias empresas, o CFC (Conselho Federal de Contabilidade) aprovou, em 2009, o Pronunciamento Técnico CPC PME - Contabilidade para Pequenas e Médias Empresas, deliberando que a partir de $1^{\circ}$ de janeiro de 2010 a referida norma já fosse adotada. Elaborado a partir do The International Financial Reporting Standard for Small and Medium-sized Entities (IRFS for SMEs), produzido pelo International Accounting Standards Board (IASB), o objetivo é transformar as diversas práticas contábeis em uma linguagem única, aceita por diversos países, viabilizando a comparabilidade das informações contábeis produzidas em países distintos. A homologação da Resolução CFC no 1.255/09 resultou na aprovação da NBC TG 1000 (Norma de Contabilidade para Pequenas e Médias Empresas), com vigência para os exercícios iniciados a partir de $1^{\circ}$ de janeiro de 2010 , inserindo as pequenas e médias empresas brasileiras no contexto da convergência das normas contábeis nacionais ao padrão internacional.

Dependendo do contexto em que se procede a análise, a definição de pequenas e médias empresas assume diferentes possibilidades. Segundo o SEBRAE/SP (2011): Não há unanimidade sobre a delimitação do segmento das micro e pequenas empresas. Observa-se, na prática, uma variedade de critérios para a sua definição, tanto por parte da legislação específica, como por parte de instituições financeiras oficiais e órgãos representativos do setor.

A aplicação das normas enunciadas pelo CPC PME é sintetizada por Prado et al (2011, p. 5):

Estão obrigadas a elaborar seus relatórios contábeis de acordo com orientações do CPC PME as empresas que não tenham obrigação pública de prestação de contas, que não transacionem suas ações na Bolsa de Valores, independente de sua forma jurídica, podendo ser Limitada (Ltda.) ou Sociedade Anônima (S.A.).

Pelo exposto, constata-se a vasta abrangência da referida norma, sendo que o universo compreendido pelo CPC PME é representativo, tanto em matéria de empresas abarcadas, quanto no que se refere ao número de profissionais da área contábil que necessitam se adequar.

Ao procederem à adoção do CPC PME as empresas devem apresentar uma declaração explícita e não reservada, em suas notas explicativas, de conformidade com o pronunciamento, o que significa dizer que todos os requerimentos da norma foram adotados, não podendo descartar nenhum item que, por julgamento daquele que a produz, ache irrelevante, a não ser que esteja explícito na norma.

R. Cont. Ufba, Salvador-Ba, v. 8, n. 3, p. 75 - 91, set-dez 2014 
O CPC PME trouxe algumas simplificações, se comparado aos demais pronunciamentos técnicos aplicáveis às empresas que têm obrigação de prestação pública de contas, porém é muito mais amplo do que a simples troca de nomes de determinados itens das demonstrações contábeis. Como afirma Silva (2011, p. 7):

A adoção das Normas Internacionais de Relatórios Financeiros (IFRS-PME) não é um
exercício meramente técnico, envolvendo o reordenamento de informações e
reclassificações nas demonstrações contábeis. A conversão para as Normas
Internacionais de Relatórios Financeiros (IFRS-PME) irá desafiar os fundamentos de
um modelo de negócios até então existente nas pequenas e médias empresas, e
fornecerá a elas uma oportunidade ímpar para reexaminar e replanejar sua
administração, através da maneira de reportar seus gerenciamentos internos.

A convergência para as normas internacionais de contabilidade aplicáveis às pequenas e médias empresas (IFRS for SMEs) também tem sido discutida em âmbito internacional, inclusive em economias emergentes como o Brasil.

Baldarelli et al (2012) mencionam que o processo de harmonização não é tarefa fácil e no caso das PME se torna ainda mais difícil, devido às necessidades informacionais dos usuários e aos custos de preparação dos relatórios contábeis. Estas autoras destacam que o IASB tenta diminuir o esforço de produção de informações contábeis pelas PME, porém, mantendo informações relevantes para os usuários e considerando os objetivos de harmonização ao mesmo tempo. Ram e Newberry (2013) corroboram essa afirmação, ressaltando que o IASB tenta minimizar as divergências entre o IFRS for SMEs e ofull IFRS (ou IFRS completo). Baldarelli et al (2012) também sugerem que aspectos culturais, diferenças institucionais, ambientais, de mercado e tributação, além da própria atitude das PME para se consolidarem e sobreviverem num mundo competitivo global, podem influenciar na adoção e utilização das IFRS for SMEs.

Nessa perspectiva, exige-se do profissional contábil o desafio de uma mudança cultural, onde a contabilidade passa a ter lugar de destaque na evidenciação das transações econômicas da entidade.

\subsection{Evidências Empíricas sobre a Contabilidade das Pequenas e Médias Empresas}

Esta subseção reúne alguns estudos empíricos sobre a contabilidade das pequenas e médias empresas.

Stroeher e Freitas (2008) verificaram que as pequenas empresas não têm interesse em informação contábil relativa à gestão do empreendimento e que a informação de maior frequência fica restrita aos assuntos de ordem fiscal, legal e burocrática. Neste estudo foram entrevistados 15 empresários e 5 contadores responsáveis em duas cidades do Vale do Taquari, Rio Grande do Sul. Para os autores, as informações contábeis fornecidas pelos escritórios de contabilidade não suprem a necessidade básica por informação legal e fiscal e os empresários não têm interesse em fazer uso pleno das informações contábeis devido a seu porte. As informações não são tempestivas, realizando apenas o papel de proteger a empresa quanto às obrigações.

Quanto à compreensibilidade das informações contábeis, Stroeher e Freitas (2008) destacam a necessidade de explicação por parte do contador. Tais autores identificaram que a contabilidade tem dificuldades de cumprir seu papel nas pequenas empresas, dentre outros fatores, pela informalidade, pois o empresário não fornece todos os dados para a escrituração contábil, prejudicando a mensuração e apresentação da real capacidade dos negócios. Concluíram que as 
informações contábeis não são úteis para as decisões organizacionais nas pequenas empresas, devido à sua característica apenas legal e fiscal.

A pesquisa de Prado et al (2011) orientou-se por um estudo exploratório que investigou o nível de utilização do CPC PME nas cidades de Araguari, Uberaba e Uberlândia, localizadas no estado de Minas Gerais. Os objetivos desta pesquisa foram determinar o nível de conhecimento e adesão ao CPC PME, a opinião dos contadores e as dificuldades enfrentadas por estes que determinaram a adesão ou não ao referido pronunciamento. Os resultados da pesquisa mostraram que a maioria dos profissionais de contabilidade afirma não ter adotado o pronunciamento nas empresas em que são responsáveis pela contabilidade e menos da metade destes profissionais sequer conhecem o conteúdo do CPC PME.

Prado et al (2011, p. 3) destacam que "esse movimento, no sentido de incluir as pequenas e médias empresas no processo de convergência das normas contábeis, requer investigações empíricas que forneçam avaliações atualizadas do processo e de eventuais impedimentos ao seu progresso". Os autores citam que os elevados custos de implementação, o nível de conhecimento dos profissionais, as diferentes necessidades dos usuários das informações e o fato de o país ter um sistema code law, podem ser considerados como desvantagens ou até empecilhos no processo de adoção das normas.

Com o objetivo de analisar se as práticas contábeis adotadas pelos profissionais da área atendem às normas do CPC PME, Rower, Bordignon e Kruger (2012) aplicaram questionários aos profissionais contábeis do município de Chapecó/SC, em uma amostra de 19 entidades prestadoras de serviços contábeis. O estudo evidenciou a necessidade de qualificação profissional para o cumprimento das exigências do CPC PME e demonstrou que $84 \%$ das empresas-clientes da amostra estão sujeitas ao pronunciamento, porém apenas $32 \%$ dos profissionais afirmam conhecer e entender a norma. Destes profissionais, $42 \%$ afirmam elaborar as demonstrações contábeis em conformidade com o CPC PME, mas somente 16\% mensuram o ativo imobilizado e estoques com base na norma.

Santa e Laffin (2012) destacaram a importância da informação contábil para a gestão de pequenas e médias empresas, relatando que são os problemas gerenciais os maiores motivos para a mortalidade destas empresas, relevantes para a economia do país. Os autores afirmam que o benefício alcançado pelas pequenas e médias empresas com as mudanças nas Normas Brasileiras de Contabilidade é um número maior de informações fornecidas pela contabilidade, que dá mais subsídios para a tomada de decisão.

Klein Júnior e Souza (2013) propuseram um roteiro para a implantação de controles patrimoniais nas pequenas e médias empresas com ênfase na sua importância para a gestão, por meio da análise do caso de uma empresa situada em Porto Alegre/RS. No caso estudado por estes autores, a implantação de uma sistemática de controle patrimonial permitiu à empresa sua adequação às normas atuais de contabilidade, além de proporcionar um controle patrimonial mais eficiente e eficaz, gerando informações mais úteis aos seus administradores (KLEIN JÚNIOR; SOUZA, 2013, p. 28).

Klein Júnior e Souza (2013, p. 27-28) destacam que:

Uma das principais ênfases da legislação contábil brasileira atual, na questão do patrimônio, é que o balanço patrimonial é formatado para a gestão da empresa e não para atender apenas ao fisco. Nesse contexto, as alterações introduzidas pelas novas normas contábeis irão contribuir também para melhorar a gestão patrimonial das PMEs. Embora possa levar um tempo para as empresas se adequarem, seja por resistência à mudança ou pelo custo inicial de implantação de controle patrimonial, é um caminho sem volta, e os profissionais da contabilidade precisam contribuir para o

R. Cont. Ufba, Salvador-Ba, v. 8, n. 3, p. 75 - 91, set-dez 2014 
esclarecimento dos empresários e a divulgação dos benefícios das modificações propostas.

A partir desses relatos é possível perceber a importância da contabilidade para as pequenas e médias empresas, representando um vasto campo de atuação ainda a ser explorado, dado o número reduzido de trabalhos na temática. O estudo bibliométrico de Anjos, Espejo e Scherer (2011) analisou a evolução temporal da produção de pesquisas científicas que relacionam Demonstrações Financeiras e Pequenas Empresas em periódicos internacionais e a adoção das abordagens positiva e normativa destas publicações. Para isso, selecionaram 72 artigos publicados entre 1925 e o primeiro semestre de 2010, constantes no portal de periódicos da CAPES (Coordenação de Aperfeiçoamento de Pessoal de Nível Superior) que continham os termos "Small Business" e "Financial Statement". Os autores observaram que em um período tão longo foram poucas publicações sobre o tema, ou seja, menos de uma publicação por ano. Albu et al (2013) investigaram as percepções dos atores envolvidos nos relatórios financeiros em quatro economias emergentes (República Checa, Hungria, Romênia e Turquia) sobre a possível implementação das IFRS para as PME, em termos de custos, benefícios e estratégia de adoção. Foram realizadas entrevistas semi-estruturadas com representantes das principais partes interessadas (preparadores, auditores, reguladores, entidades profissionais e usuários). Os autores encontraram mais apoio para a implementação das IFRS para PMEs nestes quatro países do que o sugerido pelos resultados da consulta da Comissão Europeia de 2010 para a União Europeia. As entrevistas revelaram diferenças entre os grupos de partes interessadas e entre os países em relação à abordagem preferida de implementação (adoção obrigatória, adoção voluntária ou convergência das regulamentações nacionais com as IFRS para as PME). Os resultados indicaram preferência pela abordagem de convergência, no entanto, os usuários se opõem à convergência e preferem a adoção das IFRS para as PME. Segundo os autores, este resultado é relevante no processo de tomada de decisões das entidades reguladoras nacionais, que devem equilibrar as necessidades dos vários intervenientes, mas também, objetivos políticos e econômicos do país.

Em linha com os estudos apresentados, principalmente com o de Prado et al (2011) e o de Rower, Bordignon e Kruger (2012), a presente pesquisa pretende contribuir com os trabalhos sobre demonstrações contábeis para pequenas e médias empresas e investiga a aplicabilidade do CPC PME por meio de questionamentos aos profissionais contábeis. A seção seguinte explica os procedimentos metodológicos que possibilitaram o alcance desse intento.

\section{ASPECTOS METODOLÓGICOS}

Para realizar o presente estudo foi feito um levantamento dos escritórios de contabilidade associados ao Sindicato dos Contabilistas de Uberlândia/MG, o qual revelou uma população de 450 empresas contábeis na época da pesquisa (janeiro de 2013). De posse do banco de dados, foi encaminhado um questionário a estes escritórios, via correio eletrônico, além de contatos via telefone convidando os contadores a participarem da pesquisa.

O questionário, instrumento da pesquisa, contém 13 perguntas de múltipla escolha e foi estruturado de modo a permitir uma caracterização do contador responsável e do escritório contábil, bem como, identificar se o CPC PME é adotado ou não. Outras perguntas versam sobre os procedimentos que são empregados para a elaboração das demonstrações contábeis, no intuito de identificar se o CPC PME é adotado adequadamente, e sobre fatores que influenciam ou dificultam a adoção da norma. Os procedimentos focados nas questões referem-

R. Cont. Ufba, Salvador-Ba, v. 8, n. 3, p. 75 - 91, set-dez 2014 
se à forma de mensuração e contabilização de ativos e à forma de apresentação das demonstrações contábeis. A estruturação do questionário tomou por base os questionários aplicados por Prado et al (2011) e Rower, Bordignon e Kruger (2012), procedendo-se as adaptações necessárias. Foi realizado um pré-teste no intuito de depurar o questionário antes que o mesmo fosse utilizado, seguindo-se, ainda, as recomendações de Oliveira (2011, p. 65):

\begin{abstract}
Costuma ser baixo o retorno em termos de questionários enviados e recebidos com preenchimento. Recomenda-se, então, enviar uma nota ou carta, junto do questionário, explicando a natureza da pesquisa, sua importância e a necessidade das respostas, para despertar o interesse do recebedor, com o objetivo de que ele preencha e devolva o questionário num prazo adequado ao cronograma da pesquisa.
\end{abstract}

A coleta de dados se deu no período de 10 a 31 de janeiro de 2013, ao longo do qual o questionário foi enviado duas vezes para tentar captar um maior número de respondentes, porém a maioria das respostas foi obtida através do contato telefônico. Obteve-se 84 questionários respondidos cujos dados foram analisados por meio de estatísticas descritivas, com uso de frequências absolutas e relativas, e por meio do teste Qui-quadrado. De acordo com Fávero et al (2009) o teste Qui-quadrado visa verificar se existe associação entre variáveis e é aplicado a uma amostra em que a variável nominal assume duas ou mais categorias. As hipóteses do teste Qui-quadrado são: $\mathrm{H}_{0}$ : as variáveis são independentes; $\mathrm{H}_{1}$ : as variáveis são dependentes.

As variáveis empregadas no teste foram: adoção do CPC PME, sendo "0" não adota e "1" adota; quantidade de clientes dos escritórios, quantidade de PME atendidas pelos escritórios, tempo de atuação profissional dos contadores responsáveis pelos escritórios, nível de conhecimento sobre o conteúdo do CPC PME, todas categorizadas de "1" até "5", de acordo com as escalas crescentes estipuladas no questionário; formação acadêmica dos contadores responsáveis pelos escritórios, categorizada de "1" a "4", conforme escala crescente do questionário. O nível de significância adotado para o teste neste estudo foi sig < 0,05, isto é, $95 \%$ de confiança.

\title{
4. APRESENTAÇÃO E ANÁLISE DOS RESULTADOS
}

Obteve-se o retorno de 84 questionários respondidos pelos contadores de diversos escritórios de contabilidade da cidade de Uberlândia, o que corresponde a uma amostra de, aproximadamente, 19\%. Apenas um contador de cada empresa contábil respondeu o questionário. Levando-se em conta que $45 \%$ dos escritórios contábeis da amostra possuem mais de $90 \%$ de pequenas empresas como clientes, esta pode ser considerada representativa. Essas informações podem ser observadas na Tabela 1, que ilustra o perfil da amostra.

Tabela 1 - Perfil da amostra

\begin{tabular}{lcc}
\hline \multicolumn{3}{c}{ Quantidade de clientes dos escritórios } \\
\hline Clientes & Quantidade & Frequência Relativa \% \\
\hline De 01 a 50 clientes & 31 & 37 \\
De 51 a 100 clientes & 26 & 31 \\
De 101 a 150 clientes & 17 & 20 \\
De 151 a 250 clientes & 6 & 7 \\
Mais de 250 clientes & 4 & 5 \\
\hline Total de Respostas & 84 & 100 \\
\hline
\end{tabular}

R. Cont. Ufba, Salvador-Ba, v. 8, n. 3, p. 75 - 91, set-dez 2014 
Quantidade de PME atendidas pelos escritórios

\begin{tabular}{|c|c|c|}
\hline & Quantidade & Frequência Relativa \% \\
\hline Até $30 \%$ & 6 & 7 \\
\hline De $31 \%$ a $50 \%$ & 4 & 5 \\
\hline De $51 \%$ a $70 \%$ & 12 & 14 \\
\hline De $71 \%$ a $90 \%$ & 24 & 29 \\
\hline Mais de $90 \%$ & 38 & 45 \\
\hline Total de Respostas & 84 & 100 \\
\hline \multicolumn{3}{|c|}{ Tempo de atuação profissional dos contadores responsáveis pelos escritórios } \\
\hline & Quantidade & Frequência Relativa \% \\
\hline Menos de 3 anos & 2 & 2 \\
\hline Entre 3 e 6 anos & 1 & 1 \\
\hline Entre 6 e 10 anos & 3 & 4 \\
\hline Entre 10 e 20 anos & 30 & 36 \\
\hline Mais de 20 anos & 48 & 57 \\
\hline Total de Respostas & 84 & 100 \\
\hline
\end{tabular}

Formação acadêmica dos contadores responsáveis pelos escritórios

\begin{tabular}{lcc}
\hline & Quantidade & Frequência Relativa \% \\
\hline Técnico & 36 & 43 \\
Bacharel & 41 & 49 \\
Pós-Graduado em contabilidade ou áreas afins & 6 & 7 \\
Mestre em contabilidade ou áreas afins & 1 & 1 \\
\hline Total de Respostas & 84 & 100 \\
\hline
\end{tabular}

Os dados de frequência relativa foram arredondados para facilitar as análises. Pela Tabela 1 percebe-se que $68 \%$ dos escritórios de contabilidade da amostra atendem até 100 clientes cada. Essa característica da amostra se assemelha com o encontrado por Rower, Bordignon e Kruger (2012), quando estes constataram que 79\% da amostra investigada tinham até 100 clientes. Os números indicam que todos os escritórios de contabilidade que participaram da pesquisa tem como clientes pequenas e médias empresas, corroborando os estudos de Prado et al (2011) e Rower, Bordignon e Kruger (2012).

Os contadores foram questionados, também, quanto ao tempo de atuação na área. A pesquisa foi direcionada aos contadores responsáveis pelos escritórios e os resultados revelaram a predominância da gestão destes escritórios sendo feita por profissionais que acumulam mais de vinte anos de carreira (cerca de 57\%), sendo que apenas $7 \%$ do total de entrevistados possuem até 10 anos de atuação na área, conforme mostra a Tabela 1.

No que diz respeito à formação acadêmica dos contadores participantes da pesquisa, chama a atenção o número elevado de técnicos em contabilidade, assim como o baixo número de profissionais com pós-graduação em contabilidade ou áreas afins. Prado et al (2011) encontraram situação com grande variação entre o número de técnicos $(27 \%)$ e bacharéis $(70 \%)$. Quando questionados sobre o conhecimento acerca do conteúdo do CPC PME, $64 \%$ dos entrevistados afirmaram desconhecer totalmente tais normas e apenas $7 \%$ dizem conhecer o conteúdo na íntegra. A Tabela 2 resume os dados:

R. Cont. Ufba, Salvador-Ba, v. 8, n. 3, p. 75 - 91, set-dez 2014 
Tabela 2 - Nível de conhecimento sobre o conteúdo do CPC PME

\begin{tabular}{lcc}
\hline & Quantidade & Frequência Relativa \% \\
\hline Possui conhecimento de todo o conteúdo do CPC PME & 6 & 7 \\
Está familiarizado com as determinações & 15 & 18 \\
Domina poucos aspectos & 2 & 2 \\
Apenas ouviu falar & 7 & 8 \\
Desconhece o assunto & 54 & 64 \\
\hline Total de Respostas & 84 & 100 \\
\hline
\end{tabular}

Os dados apontados na Tabela 2 contrariam os obtidos por Prado et al (2011), sendo que em tal estudo a maior parte dos contadores (40\%) respondeu que está familiarizada com as determinações, porém desconhece sua íntegra. Vale ressaltar, todavia, que o estudo de Prado et al (2011) foi realizado em três cidades da mesma região, o que pode justificar a discrepância nas informações obtidas.

Na sequência, buscou-se conhecer quantos são os escritórios da amostra que adotam as normas do CPC PME. A Tabela 3 mostra os números.

\section{Tabela 3 - Nível de adoção do CPC PME pelos escritórios de contabilidade}

\begin{tabular}{lcc}
\hline $\begin{array}{l}\text { Contadores que elaboram as demonstrações contábeis de acordo } \\
\text { com o CPC PME }\end{array}$ & Quantidade & Frequência Relativa \% \\
\hline Em nenhuma das PME clientes & 71 & 85 \\
Em até 30\% das PME clientes & 5 & 6 \\
Entre 30\% e 50\% das PME clientes & 2 & 2 \\
Em mais de 50\% das PME clientes & 4 & 5 \\
Em todas as PME clientes & 2 & 2 \\
\hline Total de Respostas & 84 & 100 \\
\hline
\end{tabular}

Faz-se aqui uma observação importante, sendo que aproximadamente apenas $7 \%$ dos entrevistados afirmaram ter o conhecimento pleno do CPC PME, porém, 15\% dos contadores afirmaram adotar o referido pronunciamento, em maior ou menor intensidade, junto a seus clientes.

A partir desses resultados, buscou-se identificar se as características relativas aos escritórios de contabilidade, aos contadores, bem como, o nível de conhecimento acerca do CPC PME influenciam a adoção desta norma. Será que o baixo índice de adoção estaria relacionado à predominância de profissionais com elevado tempo de carreira, assim como à baixa opção por cursos de pós-graduação? O teste Qui-quadrado identificou associações, ou seja, dependência, entre algumas variáveis, conforme demonstrado na Tabela 4.

Tabela 4 - Testes Qui-quadrado

\begin{tabular}{lccc}
\hline Qui-quadrado de Pearson & Valor & df & Sig. Assint. (2 lados) \\
\hline adoção*quantidade de clientes & 6,388 & 4 &, 172 \\
adoção*quantidade de PME & 1,435 & 4 &, 838 \\
adoção*tempo de atuação & 7,171 & 4 &, 127 \\
adoção*formação acadêmica & 14,991 & 3 &, 002
\end{tabular}

R. Cont. Ufba, Salvador-Ba, v. 8, n. 3, p. 75 - 91, set-dez 2014 
Pela Tabela 4 é possível observar que apenas as variáveis formação acadêmica e nível de conhecimento do CPC PME estão associadas com a adoção deste pronunciamento. Isto significa que a adoção do CPC PME pode depender do nível de escolaridade e do conhecimento acerca da norma. Entretanto, para entender melhor essa associação, foram calculados os resíduos ajustados. O resíduo ajustado tem distribuição normal com média zero e desvio padrão igual a 1. Desta forma, caso o resíduo ajustado seja maior que 1,96, em valor absoluto, pode-se dizer que há evidências de associação significante entre duas categorias. Quanto maior for o resíduo ajustado, maior a associação entre as categorias. Os resultados podem ser vistos na Tabela 5.

\section{Tabela 5 - Cálculo dos resíduos ajustados}

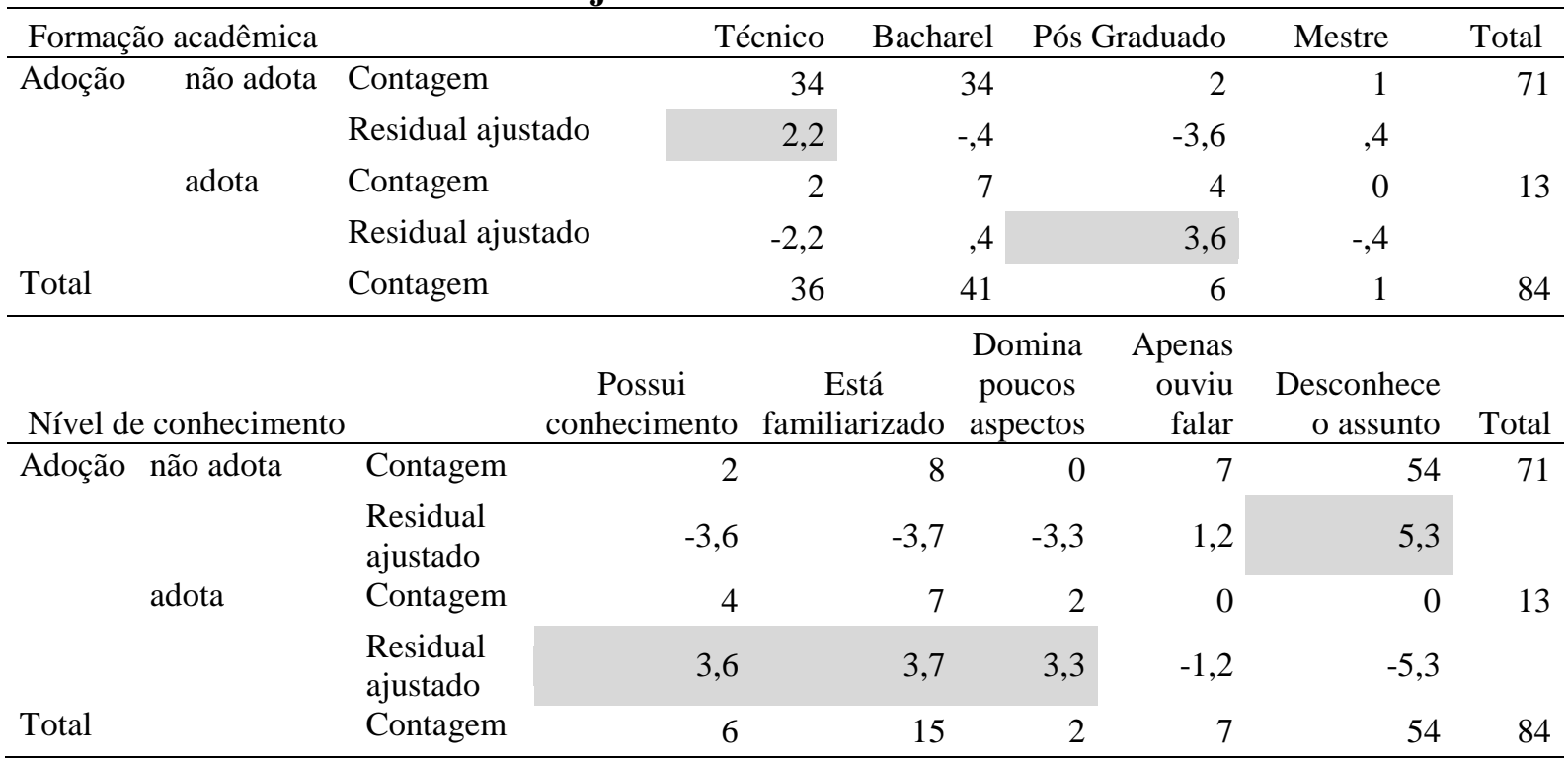

Observando a Tabela 5 fica claro que a não adoção do CPC PME está relacionada à formação de técnico em contabilidade e que a adoção está associada a uma formação mais completa, ou seja, os contadores com pós-graduação tendem a adotar o pronunciamento na elaboração das demonstrações contábeis. No que diz respeito ao nível de conhecimento do contador acerca do CPC PME, aqueles que desconhecem o assunto não adotam a norma, porém, mesmo aqueles que se consideram apenas familiarizados com as determinações da norma ou dominam poucos aspectos, adotam o pronunciamento. Assim, surge a necessidade de conhecer se o CPC PME está sendo aplicado adequadamente.

A segunda parte do questionário foi direcionada aos 13 escritórios (15\%) da amostra que afirmam adotar o CPC PME, tendo por objetivo identificar se os procedimentos estão em conformidade com a referida norma. De acordo com o item 3.3 do CPC PME: "As demonstrações contábeis não devem ser descritas como em conformidade com este Pronunciamento a não ser que estejam em conformidade com todos os requerimentos deste Pronunciamento".

Perguntou-se a estes profissionais quais empresas são contempladas pelo CPC PME. As respostas estão apresentadas na Tabela 6. 
Tabela 6 - Empresas contempladas pelo CPC PME

\begin{tabular}{lcc}
\hline Conceito de PME de acordo com o CPC PME & Quantidade & Frequência Relativa \% \\
\hline $\begin{array}{l}\text { Empresas que não têm obrigação pública de prestação de contas e } \\
\text { elaboram demonstrações contábeis para fins gerais }\end{array}$ & 8 & 62 \\
Sociedades por ações & 1 & 8 \\
Todas as empresas & 4 & 31 \\
\hline Total de Respostas & 13 & 100 \\
\hline
\end{tabular}

Apesar de afirmar que aplicam a norma nas demonstrações contábeis das pequenas e médias empresas, começa a se perceber aqui a fragilidade do conhecimento destes contadores a respeito do assunto. Obteve-se uma resposta de um profissional que acredita que esta norma deve ser aplicada apenas se a empresa tratar-se de uma sociedade anônima e outros quatro respondentes afirmaram que a norma pode ser aplicada para todas as empresas, no entanto, o item 1.5 do CPC PME deixa claro:

Se a entidade obrigada à prestação pública de contas usar este pronunciamento, suas demonstrações contábeis não podem ser descritas como se estivessem em conformidade com a Contabilidade para Pequenas e Médias Empresas (PMEs) mesmo que a lei ou regulamentação permita ou exija que este pronunciamento seja usado por empresas obrigadas à prestação pública de contas.

Ao mencionar o tratamento a ser dado ao ativo imobilizado, o CPC PME orienta que a entidade deve mensurar tal ativo no reconhecimento inicial pelo seu custo. O item 17.15 do CPC PME diz ainda que, entre outras providências: "A entidade deve mensurar todos os itens do ativo imobilizado, após o reconhecimento inicial, pelo custo menos depreciação acumulada e quaisquer perdas por redução ao valor recuperável de ativos acumuladas". Sobre os procedimentos adotados pelos 13 contadores, apenas 4 estão de acordo com a referida norma, sendo que os outros adotam procedimentos diversos, conforme mostrado na Tabela 7.

\section{Tabela 7 - Mensuração do Ativo Imobilizado}

\begin{tabular}{lcc}
\hline Tratamento do Ativo Imobilizado & Quantidade & Frequência Relativa \% \\
\hline $\begin{array}{l}\text { Considera, inicialmente, o custo original e, nos exercícios seguintes, } \\
\text { o custo menos depreciação acumulada e quaisquer perdas por } \\
\text { redução ao valor recuperável acumuladas }\end{array}$ & 4 & 31 \\
$\begin{array}{l}\text { Considera o custo histórico deduzido da depreciação acumulada } \\
\text { Considera o custo histórico menos depreciação acumulada e } \\
\text { quaisquer perdas por redução ao valor recuperável acumuladas } \\
\text { Considera o menor valor entre o valor contábil e o valor histórico }\end{array}$ & 5 & 38 \\
\hline Total de Respostas & 0 & 31 \\
\hline
\end{tabular}

Klein Júnior e Souza (2013, p. 22-23) lembram da importância de controlar adequadamente o ativo imobilizado para atender as normas contábeis:

(...) a mensuração do ativo imobilizado reveste-se de complexidade para as quais as empresas devem se preparar, tanto do ponto de vista conceitual quanto do ponto de vista de aplicação prática das normas, o que certamente envolve investimentos e adaptação dos controles do ativo para gerar as informações necessárias. Assim, a partir

R. Cont. Ufba, Salvador-Ba, v. 8, n. 3, p. 75 - 91, set-dez 2014 
de 01/01/2010, as PMEs foram obrigadas a adotar os conceitos de reconhecimento do ativo, valor residual e valor recuperável para os bens do ativo imobilizado.

Infelizmente a presente pesquisa revelou inconsistências com relação à mensuração do ativo imobilizado e à depreciação nas empresas da amostra. As práticas dos contadores relativas à depreciação do ativo imobilizado são retratadas na Tabela 8.

\section{Tabela 8 - Depreciação do Ativo Imobilizado}

\begin{tabular}{|c|c|c|}
\hline Tratamento da depreciação & Quantidade & Frequência Relativa \% \\
\hline $\begin{array}{l}\text { Considera uma vida útil estimada fixa para cada grupo de ativo } \\
\text { imobilizado }\end{array}$ & 4 & 31 \\
\hline $\begin{array}{l}\text { Contabiliza a depreciação desde quando o bem entra em operação } \\
\text { até o final de sua vida útil, independente se o bem estiver ocioso } \\
\text { no período }\end{array}$ & 7 & 53 \\
\hline $\begin{array}{l}\text { Contabiliza a depreciação em bases sistemáticas ao longo da vida } \\
\text { útil estimada para os ativos }\end{array}$ & 1 & 8 \\
\hline $\begin{array}{l}\text { Realiza revisões anuais da vida útil dos bens, independente de } \\
\text { condições tecnológicas ou do ambiente }\end{array}$ & 1 & 8 \\
\hline Total de Respostas & 13 & 100 \\
\hline
\end{tabular}

Neste questionamento, obteve-se apenas uma resposta em conformidade com o item 17.18 do CPC PME "a entidade deve alocar o valor depreciável de ativo em base sistemática ao longo da sua vida útil".

No que diz respeito aos estoques, também houve apenas uma resposta de acordo com o item 2.49 (b) do CPC PME que diz que "a entidade avalia estoques pelo menor valor entre o custo e o preço de venda estimado, menos despesas para completar a produção e vender". Na Tabela 9 é possível visualizar que a maioria dos contadores $(46 \%)$ continua utilizando o custo histórico para mensuração dos estoques e, em segundo lugar, a prática mais usual é considerar o maior valor entre o custo e o preço de venda estimado (31\%).

\section{Tabela 9 - Mensuração dos Estoques}

\begin{tabular}{lcc}
\hline Tratamento dos estoques & Quantidade & Frequência Relativa \% \\
\hline Considera o maior valor entre o custo e o preço de venda estimado & 4 & 31 \\
Considera o custo histórico & 6 & 46 \\
$\begin{array}{l}\text { Considera o preço de venda estimado } \\
\text { Considera o menor valor entre o custo e o preço de venda estimado } \\
\text { diminuído dos custos para completar a produção e despesas de } \\
\text { vendas }\end{array}$ & 1 & 15 \\
\hline Total das Respostas & 13 & 100 \\
\hline
\end{tabular}

Questionou-se, ainda, quais foram as demonstrações contábeis elaboradas tendo por base o CPC PME. Os resultados estão na Tabela 10.

Tabela 10 - Demonstrações Contábeis elaboradas de acordo com o CPC PME

\begin{tabular}{lcc}
\hline Demonstrações Contábeis & Quantidade & Frequência Relativa \% \\
\hline Balanço Patrimonial e Demonstração de Resultado & 5 & 38 \\
Balanço Patrimonial, Demonstração de Resultado e Notas & & 23 \\
$\begin{array}{l}\text { Explicativas } \\
\text { Balanço Patrimonial, Demonstração de Resultado e Demonstração }\end{array}$ & 3 & 31 \\
do Fluxo de Caixa & 4 &
\end{tabular}

R. Cont. Ufba, Salvador-Ba, v. 8, n. 3, p. 75 - 91, set-dez 2014 
Balanço Patrimonial; Demonstração de Resultado; Demonstração do Resultado Abrangente e Demonstração das Mutações do Patrimônio Líquido (quando aplicáveis); Demonstração do Fluxo de Caixa e Notas Explicativas Total de Respostas

Novamente observa-se grande equívoco por parte dos contadores, pois, apenas 1 entrevistado respondeu corretamente sobre as demonstrações contábeis a serem apresentadas de acordo com o CPC PME (item 3.17). Tal apontamento contraria parcialmente o encontrado no estudo de Rower, Bordignon e Kruger (2012), já que estes pesquisadores evidenciaram que $42 \%$ dos contadores entrevistados elaboram todas as demonstrações contábeis obrigatórias paras as pequenas e médias empresas.

Sobre os motivos que levaram os 13 escritórios de contabilidade a adotarem o CPC PME, notase que a grande motivação se deu de forma voluntária (cerca de 44\%), conforme Tabela 11. Prado et al (2011) constataram a preocupação dos contadores em atenderem prioritariamente as exigências legais, já que em seu estudo a maior parte dos respondentes disseram que a motivação para adoção do pronunciamento foi o atendimento ao CPC.

\section{Tabela 11 - Motivos para a adoção do CPC PME}

\begin{tabular}{lc}
\hline Fatores & Frequência Relativa \% \\
\hline Adesão Voluntária & 44 \\
Exigência de Clientes & 19 \\
Exigência de Órgãos públicos & 13 \\
Atendimento ao CPC & 6 \\
Exigência de Órgãos reguladores & 6 \\
Exigência de Usuários Internos & 6 \\
Exigência de Instituições Financeiras & 6 \\
\hline Total de Respostas & 100 \\
\hline
\end{tabular}

Por último, buscou-se identificar quais foram as principais dificuldades encontradas pelos 84 contadores entrevistados em relação à adoção do CPC PME para as empresas clientes, conforme pode ser visto na Tabela 12.

\section{Tabela 12 - Dificuldades para adoção do CPC PME}

\begin{tabular}{lc}
\hline & Frequência Relativa \% \\
\hline Falta de divulgação, orientação e treinamento por parte dos & 40 \\
órgãos competentes e entidades classistas & \\
Sobrecarga de trabalho e aumento de custos na prestação de & 22 \\
serviços ao cliente & 18 \\
Falta de qualificação ou treinamento para aplicar a norma & 15 \\
Falta de estrutura dos escritórios de contabilidade & 3 \\
Desconhecimento do assunto & 2 \\
Complexidade da norma & 100 \\
\hline Total de Respostas & \\
\hline
\end{tabular}

Percebe-se que os profissionais contábeis encontraram como principais fatores dificultantes para adoção do CPC PME a falta de divulgação, orientação e treinamento por parte dos órgãos competentes e entidades classistas (40\%), seguido por sobrecarga de trabalho e aumento de custos $(22 \%)$ e falta de qualificação e treinamento para aplicar a norma (18\%), que juntos somam cerca de $80 \%$ do total de respostas. A pesquisa de Rower, Bordignon e Kruger (2012) 
evidenciou que os maiores impactos causados pela adoção do CPC PME dizem respeito ao custo dos serviços prestados e à qualificação profissional, ambos com $41 \%$ cada.

\section{CONSIDERAÇÕES FINAIS}

A realização desta pesquisa permitiu verificar que existe baixa adoção do pronunciamento CPC PME por parte dos contadores entrevistados na cidade de Uberlândia/MG. Os fatores que influenciam a adoção deste pronunciamento na amostra pesquisada estão relacionados à formação acadêmica dos contadores e ao nível de conhecimento destes acerca da norma. Os resultados indicaram que os contadores com pós-graduação em contabilidade ou áreas afins, assim como aqueles que possuem algum conhecimento sobre as determinações do CPC PME tendem a adotar este pronunciamento na elaboração das demonstrações contábeis de seus clientes.

A pesquisa também revelou que existem divergências nos procedimentos contábeis executados pelos profissionais. Desse modo, observou-se que, apesar de poucos escritórios de contabilidade adotarem o CPC PME em Uberlândia/MG, nenhum dos entrevistados está seguindo adequadamente as determinações do referido pronunciamento.

Em complemento aos estudos anteriores de Prado et al (2011) e Rower, Bordignon e Kruger (2012), na prática, nenhum escritório entrevistado está apto a afirmar que adota o pronunciamento CPC PME em suas empresas clientes, pois conforme apontado na pesquisa, não seguem seus requerimentos na íntegra e não conhecem seu conteúdo adequadamente, uma vez que o encontrado, na verdade, é uma tímida transição. Conforme Prado et al (2011, p. 11) "pode-se inferir que a efetivação de tais mudanças parecem estar distantes".

A respeito de outros fatores que influenciam a adoção do CPC PME, a pesquisa apontou que a maioria dos contadores adotou o pronunciamento de forma voluntária ou pela exigência dos próprios clientes. As principais dificuldades para a adoção do CPC PME referem-se à falta de divulgação, orientação e treinamento por parte dos órgãos competentes e entidades classistas, à sobrecarga de trabalho e aumento de custos na prestação de serviços ao cliente. Importante lembrar que os resultados aqui apresentados limitam-se à amostra investigada.

Espera-se que esta pesquisa contribua com os estudos acerca da contabilidade para as pequenas e médias empresas, visto a relevância destas no contexto econômico brasileiro. Sugere-se como pesquisas futuras verificar a aplicabilidade do CPC PME em outras regiões do Brasil e avaliar outros itens patrimoniais, assim como, identificar métodos eficientes de divulgações e incentivo para aplicação destas normas.

\section{REFERÊNCIAS}

ALBU, C. N.; ALBU, N.; PALI-PISTA, S. F.; GÎRBINĂ, M. M.; SELIMOGLU, S. K.; KOVÁCS, D. M.; LUKÁCS, J.; MOHL, G.; MÜLLEROVÁ, L.; PASEKOVÁ, M.; ARSOY, A. P.; SIPAHI, B.; STROUHAL, J. Implementation of IFRS for SMEs in Emerging Economies: Stakeholder Perceptions in the Czech Republic, Hungary, Romania and Turkey. Journal of International Financial Management \& Accounting, v. 24, n. 2, p. 140-175, 2013. 
ANJOS, Raquel Predijer; ESPEJO, Márcia Maria dos Santos Bortolocci; SCHERER, Luciano Márcio. Demonstrações contábeis nas pequenas empresas: um estudo bibliométrico. Revista da Micro e Pequena Empresa, Campo Limpo Paulista, v.5, n.2, p.106-123, mai./ago. 2011.

BALDARELLI, Maria-Gabriella; DEMARTINI, Paola; MOSNJA-SKARE, Lorena; PAOLONI, Paola. Accounting Harmonization for SME-s in Europe: Some Remarks on IFRS for SME-s and Empirical Evidences. Economic Research, v. 25, n. 1, p. 1-26, 2012.

BRASIL. Lei $\mathrm{n}^{\circ} 11.638$, de 28 de dezembro de 2007. Altera e revoga dispositivos da Lei no 6.404, de 15 de dezembro de 1976, e da Lei no 6.385, de 7 de dezembro de 1976, e estende às sociedades de grande porte disposições relativas à elaboração e divulgação de demonstrações financeiras. Diário Oficial da União, Brasília, DF, 28 dez. 2007. Disponível em: <http://www.planalto.gov.br/ccivil_03/_ato2007-2010/2007/lei/111638.htm>. Acesso em 12 nov. 2012.

COMITÊ DE PRONUNCIAMENTOS CONTÁBEIS. Pronunciamento Técnico CPC PME (R1) - Contabilidade para Pequenas e Médias Empresas. Disponível em:

<http://www.cpc.org.br/pdf/CPC_PMEeGlossario_R1.pdf>. Acesso em: 19 mai. 2012.

CONSELHO FEDERAL DE CONTABILIDADE. Resolução CFC n⿳0 1.255/2009 - Aprova a NBC TG 1000 (NBC T 19.41) - Contabilidade para Pequenas e Médias Empresas. Disponível em: <http://www.cfc.org.br/sisweb/sre/detalhes_sre.aspx?Codigo=2009/001255>. Acesso em: 11 jul. 2012.

FÁVERO, Luiz Paulo; BELFIORE, Patrícia; SILVA, Fabiana Lopes; CHAN, Betty Lilian. Análise de Dados: modelagem multivariada para tomada de decisões. Rio de Janeiro: Elsevier, 2009.

KLEIN JÚNIOR, Gert Rudolfo; SOUZA, Ângela Rozane Leal de. Adequação das novas normativas contábeis de controle patrimonial à prática das pequenas e médias empresas. Pensar Contábil, Rio de Janeiro, v. 15, n. 56, p. 22-28, jan/abr. 2013.

LOPES, Alexsandro Broedel; MARTINS, Eliseu. Teoria da Contabilidade: uma nova abordagem. São Paulo: Atlas, 2007.

LUNARDI, Guilherme Lerch; DOLCI, Pietro Cunha; MAÇADA, Antonio Carlos Gastaud. Adoção de tecnologia da informação e seu impacto no desempenho organizacional: um estudo realizado com micro e pequenas empresas. Revista de Administração da USP, São Paulo, v.45, n.1, p.05-17, jan./fev./mar. 2010.

OLIVEIRA, Antônio Benedito Silva. Métodos da Pesquisa Contábil. São Paulo: Atlas, 2011.

PRADO, Thiago Alberto dos Reis; TEIXEIRA, Bruno Ricardo; BERNARDINO, Flavia Ferreira Marques; LEMES, Sirlei. A utilização do pronunciamento do CPC para as pequenas e médias empresas: um estudo nas cidades de Araguari, Uberaba e Uberlândia - MG. In: XIV SemeAd, 2011, São Paulo. Anais... São Paulo, 2011. 
RAM, Ronita.; NEWBERRY, Susan. IFRS for SMEs: The IASB'S due process. Australian Accounting Review, v. 23, n. 1, p. 3-17, 2013.

ROWER, Gerson Roberto; BORDIGNON, Andrea Carla; KRUGER, Silvana Dalmutt. Contabilidade para Pequenas e Médias Empresas: uma análise das práticas adotadas pelos profissionais contábeis. In: CONGRESSO USP DE CONTROLADORIA E CONTABILIDADE, 12, 2012. São Paulo. Anais... São Paulo, 2012.

SANTA, Stephane Louise Boca; LAFFIN, Marcos. Benefícios para as Pequenas e Médias Empresas com as mudanças nas Normas Brasileiras de Contabilidade. Revista de Contabilidade da UFBA, Salvador, v. 6, n. 1, p. 20-32, jan./abr. 2012.

SERVIÇO BRASILEIRO DE APOIO ÀS MICRO E PEQUENAS EMPRESAS DO ESTADO DE SÃO PAULO - SEBRAE/SP. Disponível em:

$<$ http://www.sebraesp.com.br/TenhoUmaEmpresa/Biblioteca/OutrosConteudos/EstudosEPesq uisas/MPEsEmNumeros/Paginas/MPEsEmNumeros.aspx>. Acesso: 13. Jul. 2012.

SILVA, Raul Corrêa da. In: SOARES, Jairo da Rocha (Coord.). Normas Internacionais de Relatórios Financeiros para Pequenas e Médias Empresas - IFRS-PME. 2011.

Disponível em: <http://www.bdobrazil.com.br/en/publicacoes.html>. Acesso em: 12 jul. 2012.

STROEHER, Ângela Maria; FREITAS, Henrique. O uso das informações contábeis na tomada de decisão em pequenas empresas. Revista de Administração da USP, São Paulo, v.1, n.1, jan./jun. 2008. 